\title{
The Use of Protoplasts to Study Innate Immune Responses
}

\author{
Ping He, Libo Shan, and Jen Sheen
}

\begin{abstract}
Summary
The use of plant protoplast transient expression system has facilitated the discovery and dissection of many signal transduction pathways in response to hormones, metabolites, and stresses. Recently, Arabidopsis protoplasts also have been used successfully to study plant innate immune responses triggered by pathogen-derived elicitors. Here, we describe the detailed protocols for studying innate immune responses, including cell death and early defense gene regulation activated by two types of elicitors, pathogen-associated molecular patterns and bacterial type III effectors in Arabidopsis protoplasts. This cellbased system simplifies the complex pathogen-plant interactions to pure individual signals and synchronized cell-autonomous responses. The application of this novel approach provides high temporal and spatial resolution to enhance our understanding of the distinct and overlapping signaling events in pathogen-associated molecular pattern- and bacterial type III effector-activated immune responses at the molecular and cellular level.
\end{abstract}

Key Words: Arabidopsis; mesophyll protoplast; innate immunity; PAMP; Avr; cell death; early defense gene regulation.

\section{Introduction}

Plants rely on innate immune responses to launch inducible defense against bacterial, fungal, and viral pathogens upon recognition of diverse pathogenderived elicitors. The elicitors are either conserved among several microbial species (pathogen-associated molecular patterns [PAMPs]) or specific to some races of a pathogen species (avirulence [Avr] or type III effectors). The recognition of PAMPs is likely mediated by receptor-like kinases with extracellular leucine-rich repeats. In Arabidopsis, FLS2 encodes an leucine-rich-repeatreceptor-like kinase as the receptor for bacterial flagellin (1). Avr or type III effectors are recognized by plant resistance $(\mathrm{R})$ proteins to trigger gene-for- 
gene resistance (2). $\mathrm{R}$ proteins are associated with plasma membrane or localized in the intracellular cytosol or nucleus to directly or indirectly interact with avr gene products that are secreted and translocated by bacterial type III secretion system into plant cells $(3,4)$. So far, more than $40 R$ genes have been identified in diverse plant species, but the signal transduction pathways activated by $\mathrm{R}$ proteins are still poorly understood $(3,5,6)$. Extensive genetic screens have led to the isolation of many important components in gene-for-gene resistance and PAMP-mediated basal resistance (5-7). However, their biochemical functions and molecular actions in defense responses are largely unknown.

It has been widely assumed that PAMP and Avr trigger mostly convergent innate immune responses, including calcium influx, kinase activation, oxidative signaling, transcription reprogramming and, in some cases, programmed cell death $(\mathbf{8 , 9})$. Recently, analyses of global gene expression profiles have suggested that similar defense gene expression programs are shared by compatible (disease caused by virulent bacteria) and incompatible (resistance to avirulent bacteria) plant-pathogen interactions at the genome level (10). However, because the whole plant-pathogen interactions display complex responses stimulated simultaneously by a large array of extracellular and intracellular pathogen elicitors, the traditional approach provided limited resolution in dissecting the molecular mechanisms of early defense signaling events at the cellular level.

The use of transient gene expression in a cell-based system has facilitated the rapid discoveries of signal transduction pathways in many multicellular organisms. The freshly isolated Arabidopsis mesophyll protoplasts display physiological and cell-autonomous responses to a broad spectrum of signals, including light, sugar, auxin, cytokinin, abscisic acid, hydrogen peroxide, and stresses, similar to those found in intact tissues and plants $(\mathbf{1 1}, \mathbf{1 2})$. These protoplasts also have been used to investigate cell death induced by a fungal elicitor fumonisin B1 and a type III effector AvrRpt2 $(13,14)$. Notably, Arabidopsis mesophyll protoplasts have been developed to study plant innate immune responses, including activation of mitogen-activated protein kinase cascades and WRKY transcription factors triggered by flagellin (15). Future applications of the protoplast transient expression system could facilitate the dissection and comparison of different types of immune responses triggered by individual pathogen-derived elicitors at the cellular and molecular level. The protoplast system provides unique opportunities to explore the elusive early signaling events in plant disease resistance.

We have demonstrated that protoplasts could be transfected with bacterial $a v r$ genes under the control of a constitutive or inducible promoter, or treated with different PAMPs to study cell death, defense gene regulation, protein degradation and interaction, and kinase activation (Fig. 1). The same approach 


\section{Arabidopsis Protoplast System}

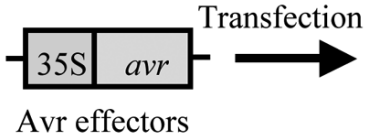

Avr effectors

PAMPs

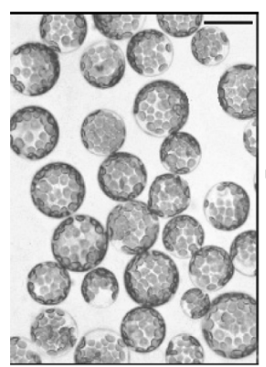

Protoplasts

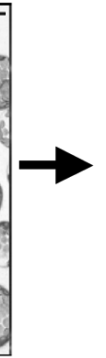

Protein activity

Protein degradation

Protein localization

Protein-protein interaction

Kinase activation

Defense gene regulation

Cell death (HR)

Signaling events

Fig. 1. The use of protoplast transient assays to study early signaling events mediated by Avr and pathogen-associated molecular pattern. $35 \mathrm{~S}$ is the constitutive promoter derived from cauliflower mosaic virus. HR, hypersensitive response.

could be used to study the functions of R proteins and other signaling components in the defense network. In combination with genetic, genomic, proteomic, and computational tools, this powerful cell-based system will broaden our understanding the signal transduction mechanisms of plant innate immunity.

\section{Materials}

\subsection{Construction of the Plant Expression Plasmids}

1. Effector constructs: clone the desired coding region of avr genes, $R$ genes, or other signaling genes into a plant expression vector behind the constitutive $35 \mathrm{~S}$ promoter or an inducible promoter $(\mathbf{1 6}, \mathbf{1 7})$.

2. Reporter constructs: fuse the promoter of various target genes with a reporter gene, such as the $L U C$ (firefly luciferase), GFP (green fluorescent protein), or GUS ( $\beta$-glucuronidase) genes (16-18).

\subsection{Protoplast Isolation and Transfection}

1. Plant material: 4-wk-old Arabidopsis plants (Col-0 or Ler) grown in soil in the greenhouse or growth chamber $\left(30-65 \%\right.$ relative humidity, $20-25^{\circ} \mathrm{C}, 50-100 \mu$ $\mathrm{mol} / \mathrm{m}^{-2} / \mathrm{s}$ light, 10 - to 13 -h photoperiod).

2. Enzyme solution: $1.5 \%$ cellulase R10, 0.4\% macerozyme R10, 0.4 M mannitol, $20 \mathrm{~m} M \mathrm{KCl}, 20 \mathrm{~m} M$ MES, pH 5.7

3. $0.45-\mu \mathrm{m}$ Filter.

4. Razor blades.

5. Desiccator.

6. 35- to $75-\mu \mathrm{m}$ nylon mesh.

7. 30-mL Round-bottom polypropylene tubes.

8. Hemacytometer.

9. 2-mL Round-bottom tubes. 
10. $40 \%(\mathrm{w} / \mathrm{v})$ polyethylene glycol (PEG) solution: To make $10 \mathrm{~mL}$ of PEG solution, add $4 \mathrm{~g}$ of PEG4000 (Fluka, cat. no. 81240) into $3 \mathrm{~mL}$ of $\mathrm{H}_{2} \mathrm{O}, 2.5 \mathrm{~mL}$ of $0.8 \mathrm{M}$ mannitol, and $1 \mathrm{~mL}$ of $1 \mathrm{M} \mathrm{CaCl}_{2}$.

11. W5 solution: $154 \mathrm{~m} M \mathrm{NaCl}, 125 \mathrm{~m} M \mathrm{CaCl}_{2}, 5 \mathrm{~m} M \mathrm{KCl}, 2 \mathrm{~m} M \mathrm{MES}$ pH 5.7.

12. MMg solution: $0.4 M$ mannitol, $15 \mathrm{~m} M \mathrm{MgCl}_{2}, 4 \mathrm{~m} M \mathrm{MES}$ pH 5.7.

13. WI solution: $0.5 M$ mannitol, $20 \mathrm{~m} M \mathrm{KCl}, 4 \mathrm{~m} M \mathrm{MES} \mathrm{pH}$ 5.7.

14. Tissue culture plates (6-well, 12-well, or 24-well).

15. PAMP: Flg22, the conserved 22 amino acids of flagellin, chemically synthesized according to the published peptide sequence (19).

\subsection{Immune Response Assays}

1. Light microscope.

2. Evans blue (Sigma).

3. Fluorescent microscope.

4. YO-PRO-1 (Molecular Probes, Y-3603).

5. 4-Methylumbelliferyl- $\beta$-D-glucuronide (MUG).

6. Fluorometer.

7. Cell lysis buffer: $25 \mathrm{~m} M$ Tris-phosphate pH 7.8, $2 \mathrm{~m} M$ 1, 2-diaminocyclohexane$N, N, N, N$-tetraacetic acid, $10 \%$ glycerol, $1 \%$ Triton X-100, $2 \mathrm{~m} M$ dithiothreitol (DTT).

8. Luciferase assay substrate (Promega, E1501).

9. Luminometer (Monolight ${ }^{\mathrm{TM}}$ 3010, BD Bioscience).

10. TRIzol Reagent (Invitrogen).

11. Oligo(dT) $(500 \mathrm{ng} / \mu \mathrm{L}$; Invitrogen $)$.

12. dNTP (Mix of dATP, dTTP, dGTP, and dCTP; New England Biolabs).

13. $5 \mathrm{X}$ first strand buffer (Invitrogen).

14. 0.1 $M$ DTT (Invitrogen).

15. RNase inhibitor ( $40 \mathrm{U} / \mu \mathrm{L}$, Invitrogen $)$.

16. M-MLV reverse transcriptase (200 U/ $\mu \mathrm{L}$, Invitrogen).

17. RNase-free DNase I (Invitrogen).

\section{Methods}

\subsection{Protoplast Isolation}

1. Prepare enzyme solution (see Note $\mathbf{1}$ ).

2. Heat the enzyme solution at $55^{\circ} \mathrm{C}$ for $10 \mathrm{~min}$ to inactivate proteases and enhance enzyme solubility.

3. Cool the solution to room temperature before adding $10 \mathrm{mM} \mathrm{CaCl}_{2}$ and $0.1 \%$ bovine serum albumin (Sigma, A7906).

4. Pass the solution through a $0.45-\mu \mathrm{m}$ filter into a Petri dish.

5. Cut well-expanded Arabidopsis leaves (usually the middle section of the third or fourth pair of true leaves approx $1-1.5 \mathrm{~cm}$ in length) into $0.5-\mathrm{mm}$ strips with fresh razor blades and digest the leaf strips in the enzyme solution in a Petri dish (see Note 2).

6. Cover the Petri dish with the foil and apply vacuum infiltration by using a desiccator for $30 \mathrm{~min}$. 


\section{Arabidopsis Protoplast System}

7. Continue the digestion without vacuum or shaking for another $2.5-3 \mathrm{~h}$. The digestion time may vary depending on the material and experimental goals.

8. Release the protoplasts by gently shaking the Petri dish by hand or use a shaker at $80 \mathrm{rpm}$ for $1 \mathrm{~min}$. Be gentle with the protoplasts. Some leaves now turn transparent and the enzyme solution becomes green.

9. Add equal volume of W5 solution to facilitate protoplast centrifugation.

10. Filter the enzyme solution containing protoplasts with a $35-$ to $75-\mu \mathrm{m}$ nylon mesh into a $30 \mathrm{~mL}$ round-bottom tube.

11. Pellet the protoplasts by spinning for $2 \mathrm{~min}$ at $100 \mathrm{~g}$ or speed 3 using an IEC clinical centrifuge.

12. Resuspend the protoplasts in $0.5 \mathrm{~mL}$ of $\mathrm{W} 5$ solution by gently shaking.

13. Count protoplasts using a hemacytometer under the light microscope and adjust the protoplasts in the W5 solution to a density of $2 \times 10^{5} / \mathrm{mL}$.

14. Keep the protoplasts on ice for at least $30 \mathrm{~min}$ in the $\mathrm{W} 5$ solution to allow recovery from isolation stress.

15. The protoplasts should settle to the bottom of the tube in 5-10 min. Before PEG$\mathrm{Ca}^{2+}$ transfection, pipet the W5 solution out and resuspend the protoplasts in $\mathrm{MMg}$ solution at a density of $2 \times 10^{5} / \mathrm{mL}$.

\subsection{PEG Transfection, PAMP Treatment, and Incubation}

1. Prepare $40 \%$ (w/v) PEG solution with $0.2 \mathrm{M}$ mannitol and $100 \mathrm{~m} M \mathrm{CaCl}_{2}$.

2. Take out the plasmid DNA from the $-20^{\circ} \mathrm{C}$ freezer and thaw it completely (see Note 3).

3. Add $20 \mu \mathrm{L}(20-40 \mu \mathrm{g})$ of the mixed effector and reporter DNA into a roundbottom $2 \mathrm{~mL}$ tube (see Note 4 ).

4. Add $200 \mu \mathrm{L}$ of protoplasts in MMg solution prepared from Subheading 3.1.15. into the tube (see Note 5).

5. After adding protoplasts, immediately add $220 \mu \mathrm{L}$ of $40 \%$ PEG into the tube and mix well gently.

6. Incubate at room temperature $\left(23^{\circ} \mathrm{C}\right)$ for $5-30 \mathrm{~min}$.

7. Stop the transfection by adding $0.8 \mathrm{~mL} \mathrm{W5}$ solution and mix well.

8. Spin at $100 \mathrm{~g}$ for $2 \mathrm{~min}$ and remove PEG.

9. Resuspend the protoplasts gently with $100 \mu \mathrm{L} / \mathrm{WI}$.

10. Add the protoplasts into a six-well tissue culture plate with $1 \mathrm{~mL}$ of WI (see Note 6).

11. Treat the protoplasts with PAMPs (optional; see Note 7).

11. Incubate the protoplasts under desirable conditions (see Note 8).

12. After incubation for 2 to $16 \mathrm{~h}$, protoplasts could be investigated immediately for cell death (see Subheading 3.3.1.), GFP expression, protein localization, or gene expression. (see Note 9).

13. Alternatively, harvest protoplasts by centrifugation at $100 \mathrm{~g}$ for $2 \mathrm{~min}$ and remove the supernatant. Freeze and store the samples at $-80^{\circ} \mathrm{C}$ until ready for diverse assays.

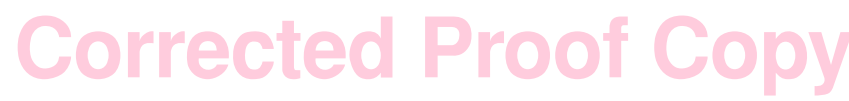




\subsection{Immune Response Assays}

\subsubsection{Cell Death Assays}

\subsubsection{Evans Blue Staining}

1. Add Evans blue dye to the protoplasts in WI solution to a final concentration of $0.04 \%$.

2. Incubate for $10 \mathrm{~min}$ at room temperature.

3. Determine the dead (stained blue) and viable (unstained) cells under a light microscope.

\subsubsection{YO-PRO-1 STAINING}

1. Add YO-PRO-1 to the protoplasts in WI solution to a final concentration of $0.5 \mu M$.

2. Determine the dead cells (intense green fluorescence and nuclear fragmentation in the nuclei) under a fluorescent microscope.

\subsubsection{Reporter Gene Assays}

\subsubsection{LuCIFERASE Activity Assay}

1. Take out the samples from $-80^{\circ} \mathrm{C}$ freezer and add $100 \mu \mathrm{L}$ of cell lysis buffer when they are still frozen (see Note 10).

2. Vortex vigorously for $2 \mathrm{~s}$ to lyse the protoplasts and keep the lysate on ice.

3. Spin down cell debris at 8,000 to $10,000 \mathrm{~g}$ for $1 \mathrm{~min}$ at $4^{\circ} \mathrm{C}$.

4. Use 5 to $50 \mu \mathrm{L}$ of cell extract to measure luciferase activity by using luciferase assay substrate with a luminometer (see Note 11).

\subsubsection{GUS ACTIVITY AsSAY}

1. Add $10 \mu \mathrm{L}$ of cell extract prepared from Subheading 3.3.2.1., step 3, into $90 \mu \mathrm{L}$ of $1 \mathrm{~m} M$ MUG in $10 \mathrm{mM}$ Tris- $\mathrm{HCl}, \mathrm{pH} 8.0$, and $2 \mathrm{mM} \mathrm{MgCl} 2$, and mix well.

2. Incubate at $37^{\circ} \mathrm{C}$ for 30 to $90 \mathrm{~min}$.

3. Add $0.9 \mathrm{~mL}$ of $0.2 \mathrm{MNa}_{2} \mathrm{CO}_{3}$ to stop the reaction.

4. Measure the fluorescence of MU using a fluorometer.

\subsubsection{Reverse Transcription Polymerase Chain Reaction Assay}

1. Isolate total RNA by using TRIzol Reagent (Invitrogen) according to the handbook. Add $0.4 \mathrm{~mL}$ of TRIzol for $8 \times 10^{4}$ protoplasts (see Note 12).

2. Mix $1 \mu \mathrm{g}$ of total RNA, $0.1 \mu \mathrm{L}$ of oligo(dT) $(500 \mathrm{ng} / \mu \mathrm{L})$ and RNase-free $\mathrm{H}_{2} \mathrm{O}$ in a final volume of $14 \mu \mathrm{L}$.

3. Heat the mix at 65 to $70^{\circ} \mathrm{C}$ for $5 \mathrm{~min}$ and chill on ice.

4. Briefly spin down the samples.

5. Add $6 \mu \mathrm{L}$ of cDNA synthesis cocktail ( $4 \mu \mathrm{L}$ of $5 \mathrm{X}$ first-strand buffer, $1 \mu \mathrm{L}$ of $2.5 \mathrm{~m} M \mathrm{dNTP}, 0.4 \mu \mathrm{L}$ of $0.1 M \mathrm{DTT}, 0.4 \mu \mathrm{L}$ of RNase inhibitor, and $0.2 \mu \mathrm{L}$ of reverse transcriptase). 


\section{Arabidopsis Protoplast System}

6. Incubate at $42^{\circ} \mathrm{C}$ for $1 \mathrm{~h}$.

7. Add $20 \mu \mathrm{L}$ of $\mathrm{H}_{2} \mathrm{O}$.

8. Take $1 \mu \mathrm{L}$ of the first-strand cDNA template for each polymerase chain reaction (PCR) using primers of the interested genes or control genes, such as genes encoding actin, ubiquitin, or tubulin (see Notes 13-15).

9. Alternatively, take 0.1 to $0.2 \mu \mathrm{L}$ of complementary DNA template for real-time PCR analysis.

\section{Notes}

1. Prepare $10 \mathrm{~mL}$ of solution to digest 10 to 20 leaves, which could yield approximately one million protoplasts.

2. The growth condition of plants is most critical for experimental reproducibility. Researchers in each laboratory may need to work out the best plant growth conditions. The well-expanded third and fourth pairs of leaves are recommended for the protoplast isolation.

3. The quality of DNA is very important for protoplast transfection. Poor-quality DNA may kill protoplasts and fail to produce any results. It is recommended to use $\mathrm{CsCl}$ gradients for Maxi-plasmid DNA isolation. The protocol could be downloaded at http://genetics.mgh.harvard.edu/sheenweb/protocols_reg.html.

4. The ratio of effector and reporter DNA could vary from 2:1 to 4:1.

5. The experiments can be easily scaled up or down as long as the recommended DNA/protoplasts ratio is followed. Use $200 \mu \mathrm{L}$ of $\left(4 \times 10^{4}\right)$ cells for most experiments, such as Western blot analysis and kinase activation. However, reporter enzyme assays only require $50 \mu \mathrm{L}\left(1 \times 10^{4}\right)$ cells.

6. To prevent sticking of protoplasts to the plastic, the plates could be coated with $5 \%$ calf serum for 1 second before use. You can also use 12- or 24-well tissue culture plates for small amount of cells.

7. The protoplasts could be treated with different PAMPs, such as bacterial flagellin and lipopolysaccharide, and fungal chitin.

8. The incubation conditions, such as light and temperature, depend on the purpose of experiments. For most experiments, protoplasts could be incubated at room temperature under low light $\left(30-50 \mu \mathrm{mol} / \mathrm{m}^{-2} / \mathrm{s}\right)$.

9. The incubation time varies in different assays. The incubation time is 3 to $6 \mathrm{~h}$ for Western blot analysis and reporter enzyme assay and 1 to $6 \mathrm{~h}$ for reverse transcription (RT)-PCR analysis. The kinase activation could be detected within minutes after PAMP treatment.

10. Add DTT in cell lysis buffer right before use.

11. Dilute the cell extract with cell lysis buffer if the reading is over the linear range of the luminometer.

12. The RNA yield is 2 to $3 \mu \mathrm{g}$ for $8 \times 10^{4}$ protoplasts, which is sufficient to analyze 40 to 50 genes by RT-PCR.

13. The number of PCR cycles depends on the abundance of the tested genes. It is usually 25 to 35 cycles.

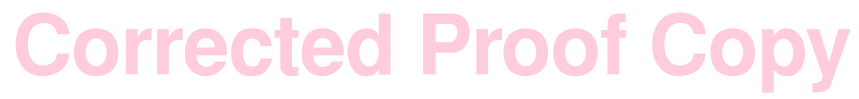


14. It is necessary to carry out a control PCR using RNA as template without RT. If a PCR product is amplified from the control reaction, this means that there is genomic DNA contamination in your RNA samples. RNA samples could be treated with RNase-free DNase I (Invitrogen) to remove DNA before RT.

15. Try to design RT-PCR primers to cover an intron so that the size of PCR product from cDNA is smaller than that from genomic DNA, or to design one primer covering the sequences from two exons, so that the primer can only anneal to the cDNA but not genomic DNA.

\section{Acknowledgments}

This work was supported by the National Science Foundation and the National Institute of Health.

\section{References}

1. Gomez-Gomez, L. and Boller, T. (2000) FLS2: an LRR receptor-like kinase involved in the perception of the bacterial elicitor flagellin in Arabidopsis. Mol. Cell 5, 1003-1011.

2. Flor, H. H. (1971) Current status of the gene-for-gene concept. Annu. Rev. Phytopathol. 9, 275-296.

3. Dangl, J. L. and Jones, J. D. (2001) Plant pathogens and integrated defence responses to infection. Nature 411, 826-833.

4. Galan, J. E. and Collmer, A. (1999) Type III secretion machines: bacterial devices for protein delivery into host cells. Science 284, 1322-1328.

5. Martin, G. B., Bogdanove, A. J., and Sessa, G. (2003) Understanding the functions of plant disease resistance proteins. Annu. Rev. Plant Biol. 54, $23-61$.

6. Belkhadir, Y., Subramaniam, R., and Dangl, J. L. (2004) Plant disease resistance protein signaling: NBS-LRR proteins and their partners. Curr. Opin. Plant Biol. 7, 391-399.

7. Glazebrook, J. (2001) Genes controlling expression of defense responses in Arabidopsis: 2001 status. Curr. Opin. Plant Biol. 4, 301-308.

8. McDowell, J. M. and Dangl, J. L. (2000) Signal transduction in the plant immune response. Trends Biochem Sci. 25, 79-82.

9. Espinosa, A. and Alfano, J. R. (2004) Disabling surveillance: bacterial type III secretion system effectors that suppress innate immunity. Cell. Microbiol. 6, $1027-1040$.

10. Tao, Y., Xie, Z., Chen, W., et al. (2003) Quantitative nature of Arabidopsis responses during compatible and incompatible interactions with the bacterial pathogen Pseudomonas syringae. Plant Cell 15, 317-330.

11. Tena, G., Asai, T., Chiu, W.-L., and Sheen, J. (2001) Plant MAP kinase signaling cascades. Curr. Opin. Plant Biol. 4, 392-400.

12. Sheen, J. (2001) Signal transduction in maize and Arabidopsis mesophyll protoplasts. Plant Physiol. 127, 1466-1475.

13. Asai, T., Stone, J. M., Heard, J. E., et al. (2000) Fumonisin B1-induced cell death in Arabidopsis protoplasts requires jasmonate-, ethylene-, and salicylate-dependent signaling pathways. Plant Cell 12, 1823-1836. 


\section{Arabidopsis Protoplast System}

14. Wu, Y., Wood, M. D., and Katagiri, F. (2003) Direct delivery of bacterial avirulence proteins into resistant Arabidopsis protoplasts leads to hypersensitive cell death. Plant J. 33, 131-137.

15. Asai, T., Tena, G., Plotnikova, J., et al. (2002) MAP kinase signalling cascade in Arabidopsis innate immunity. Nature 415, 977-983.

16. Kovtun, Y., Chiu, W.-L., Zeng, W., and Sheen, J. (1998) Suppression of auxin signal transduction by a MAPK cascade in higher plants. Nature 395, 716-720.

17. Yanagisawa, S., Yoo, S., and Sheen, J. (2003) Differential regulation of EIN3 stability by glucose and ethylene signalling in plants. Nature $\mathbf{4 2 5}, 521-525$.

18. Kovtun, Y., Chiu, W.-L., Tena, G., and Sheen, J. (2000) Functional analysis of oxidative stress-activated MAPK cascade in plants. Proc. Natl. Acad. Sci. USA 97, 2940-2945.

19. Felix, G., Duran, J., Volko, S., and Boller, T. (1999) Plants have a sensitive perception system for the most conserved domain of bacterial flagellin. Plant $J$. 18, 265-276. 
